\title{
SOCIOLOGICAL AND STATISTICAL ANALYSIS BASED ON SURVEY AT THE YEREVAN AMERICAN CORNER
}

\author{
Goharik Petrosyan ${ }^{1 凶}$, Artur Tadevosyan 2 四 \\ ${ }_{1}^{1}$ PHD, Assistant Professor, Plekhanov Russian University of Economics, Yerevan branch, \\ International Scientific Educational Centre of NAS RA, Armenian State Pedagogical University, \\ Armenia \\ 2 PHD, Assistant Professor, Armenian State Pedagogical University, Armenia
}

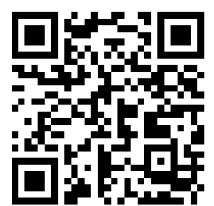

DOI: https://doi.org/10.29121/IJOEST.v4.i6.2020.130

Article Type: Research Article

Article Citation: Goharik

Petrosyan, and Artur Tadevosyan.

(2020). SOCIOLOGICAL AND

STATISTICAL ANALYSIS BASED ON

SURVEY AT THE YEREVAN

AMERICAN CORNER. International

Journal of Engineering Science

Technologies, 4(6), 39-48.

https://doi.org/10.29121/IJOEST.v

4.i6.2020.130

Received Date: 01 November 2020

Accepted Date: 17 December 2020

Keywords:

American Corner

Various Meetings

Public Talks

SPSS

Social Analysis

\section{ABSTRACT}

Rapid social, economic, technological changes in the country leave their mark on each member of the society; alter their tastes, expectations, and needs. The visitors of the Yerevan American Corner are not an exception. Thus, a necessity of a detailed analysis of the visitors' demands and behavior arises, in order to amend or expand the realm of the service, to raise the popularity of the corner and to attract more visitors. With this purpose, we offer to conduct polls and interviews among users of the American Corner, to do a specific social analysis of programs and services. Overall, 550 people will take part in the survey.

The analyses will help to understand the attitude of patrons, nonpatrons and random visitors towards the Yerevan American Corner (its space, resources, activities, projects, services, technical devices, and staff). This will also help to evaluate the effectiveness of current activities and services, such as clubs, courses, public talks and various meetings.

\section{INTRODUCTION}

The first American Space in Armenia opened in April 2005 with the inauguration of the Yerevan American Corner in partnership with the Yerevan City Central Library. There are now five American Corners located in Yerevan, Gyumri, Vanadzor, Kapan, and Charentsavan.

The Corners are staffed by bilingual Armenian library personnel who will be able to assist patrons interested in specific information about the United States.

American Corner Yerevan is a joint partnership program between City Central Library after Av. Isahakyan and U.S. Embassy in Armenia. Besides providing English language books, magazines, DVDs and ebooks (kindles), they also organize various events, such as lectures, presentations, discussions, podcast interviews, story hours for kids etc.

(C) 2020 The Author(s). This is an open access article distributed under the terms of the Creative Commons Attribution License, which permits unrestricted use, distribution, and reproduction in any medium, provided the original author and source are credited. 
They cooperate with local and international organizations as a result of which can always meet native speakers here, who conduct English language Clubs and Courses, such as kids club, teenage club, reading and debate club, movie club etc. [1], [2]. Sociological analysis was carried out from 10 ${ }^{\text {th }}$ of September 2018 to 22 ${ }^{\text {nd }}$ March 2019.

\section{SURVEY FORMS AND STATISTICAL ANALYSIS WITH SPSS}

For this social analysis, four survey forms were created and used. Below the first form is attached (see fig. *).

Survey form 1
1. How often do you visit Yerevan American Corner?
Almost every day
Once a week
Once in two weeks
Once a month
Several times a year
other

2. Why do you visit the comer?

- To study

- To improve my professional knowledge

- To read books, magazines

- To get new information/knowledge about the

- To broaden my vision and communicate

- To participate in cultural, educational and entertaining programs

- To spend my free time
3. I only read books and don't participate in language lessons, clubs, public talks, because...

- I don't have enough time

- Inconvenient scheduling (would prefer the activities to start in the morning)

- Inconvenient scheduling (would prefer the activities to start in the evening)

- Luck of information

- Uninteresting programs/projects

- Not sufficient language skills

- I've participated before, but now I don't, because ...

- Other

4. I like ....... (please numerate 1 to 9 according to your preference)
- Getting help to find the book I need

- Being able to check out magazines

- Access to computer and internet

- Being notified via email/Facebook page about the activities

- Getting information about US

- Modern and comfortable design of the room.

5. Do you think that the book collecting is sufficient?

- Yes

- No

- Partially

- If no, please provide details

6. When having any issues/question while using the corner I get help from

o the librarian

- Announcement board, flyers, informative leaflets

- The corner's Facebook/web page

- I try to find the solution myself.

- I never find answers to my questions.

- Other

7. What don't you like at the comer.

- The quality of the services and activities

- Luck of online user support

- Luck of professionalism of the librarians

- Luck of information about the corner's services and activities

- Inconvenient design, setting of the room

- Working hours, schedule

- Insufficient book collections

- Other

8. What type of information are you more interested in?

- Sociology

- Psychology 
Goharik Petrosyan, and Artur Tadevosyan

Politics

- Philosophy

History

Pedagogy

Linguistics

Natural Science

Economics

Legal

Environment

Marketing

Information technologies

Art

Fiction

Other

9. Have you ever checked out electronic readers (Kindles) or audiobooks

- Yes

- No

- I didn't know about it

10. To be comfortable at the comer I need:

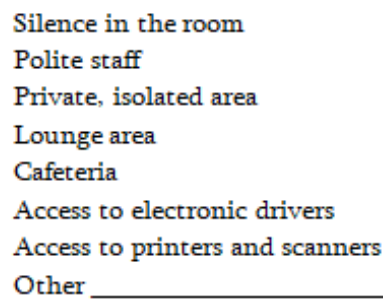

\section{Social details of the user}
1. Age
$14-20$
21-30
$31-40$
$45-50$
$51-60$
60 and older

Figure 1: Survey form

The following table and pictures (Table1 - Table6, fig1 - fig6) are based on statistical and sociological research completed trough the SPSS program [3], [4], [5], [6], [7], [8], [9], [10].

Table 1: Result of question 1

\begin{tabular}{|c|c|c|c|c|c|}
\hline \multicolumn{2}{|c|}{ Question1 } \\
\hline \multicolumn{1}{|c|}{} & Frequency & Percent & \\
\hline \multirow{7}{*}{ valid } & English language courses & 67 & 59,8 & 59,8 & 59,8 \\
\cline { 2 - 6 } & Reading club & 12 & 10,7 & 10,7 & 70,5 \\
\cline { 2 - 6 } & Discussion club & 13 & 11,6 & 11,6 & 82,1 \\
\cline { 2 - 6 } & Movie club & 6 & 5,4 & 5,4 & 87,5 \\
\cline { 2 - 6 } & Round table discussions & 1 &, 9 &, 9 & 88,4 \\
\cline { 2 - 6 } & Public talks and discussions & 5 & 4,5 & 4,5 & 92,9 \\
\cline { 2 - 6 } & Workshop & 5 & 4,5 & 4,5 & 97,3 \\
\cline { 2 - 6 } & Other & 2 & 1,8 & 1,8 & 99,1 \\
\cline { 2 - 6 } & \multicolumn{5}{|l}{} \\
\hline
\end{tabular}

$\underline{\text { International Journal of Engineering Science Technologies }}$ 
Sociological and Statistical Analysis Based on Survey at The Yerevan American Corner

\begin{tabular}{|c|c|c|c|c|c|}
\hline \multicolumn{4}{|c|}{} & \multicolumn{4}{|c|}{} \\
\cline { 2 - 5 } & 9 & 1 &, 9 &, 9 & 100,0 \\
\cline { 2 - 5 } & Total & 112 & 100,0 & 100,0 & \\
\hline
\end{tabular}

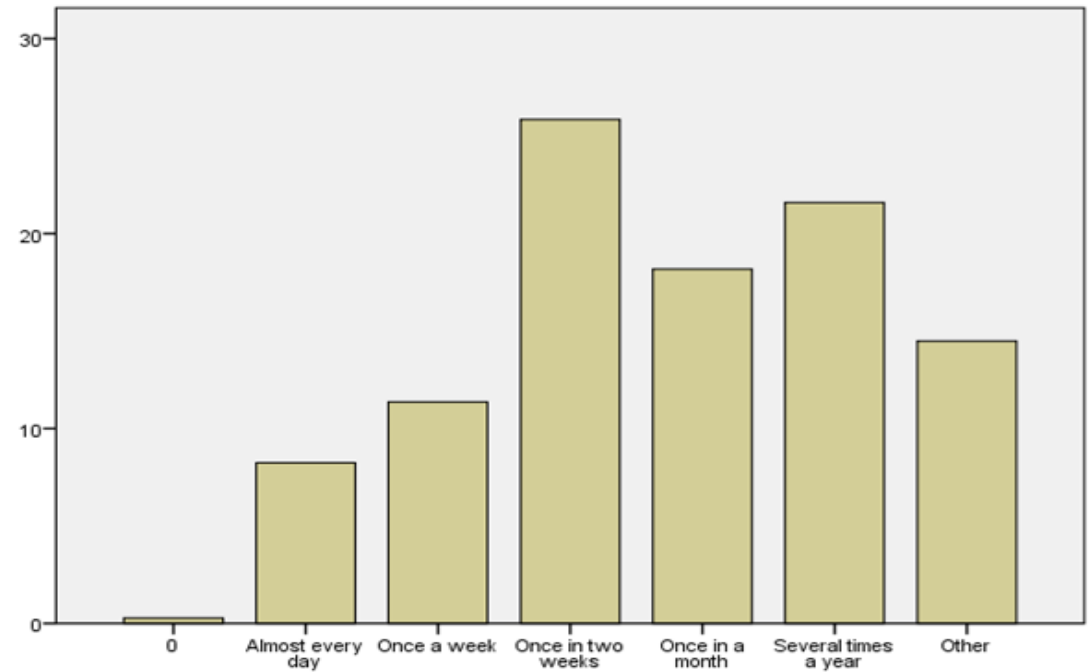

Figure 1: Histogram of question 1

Table 2: Results of question 2

\begin{tabular}{|c|c|c|c|c|c|}
\hline \multicolumn{6}{|c|}{ Question2 } \\
\hline & & \multicolumn{4}{|c|}{ FrequencyPercentValid PercentAccumulated Percent } \\
\hline \multirow[t]{8}{*}{ valid } & 0 & 2 & 1,8 & 1,8 & 1,8 \\
\hline & To improve English language skills & 88 & 78,6 & 78,6 & 80,4 \\
\hline & For personal development versatile & 13 & 11,6 & 11,6 & 92,0 \\
\hline & To communicate with native speaker & 3 & 2,7 & 2,7 & 94,6 \\
\hline & To socialize & 3 & 2,7 & 2,7 & 97,3 \\
\hline & For entertainment & 1 & ,9 & ,9 & 98,2 \\
\hline & Other & 2 & 1,8 & 1,8 & 100,0 \\
\hline & Total & 112 & 100,0 & 100,0 & \\
\hline
\end{tabular}

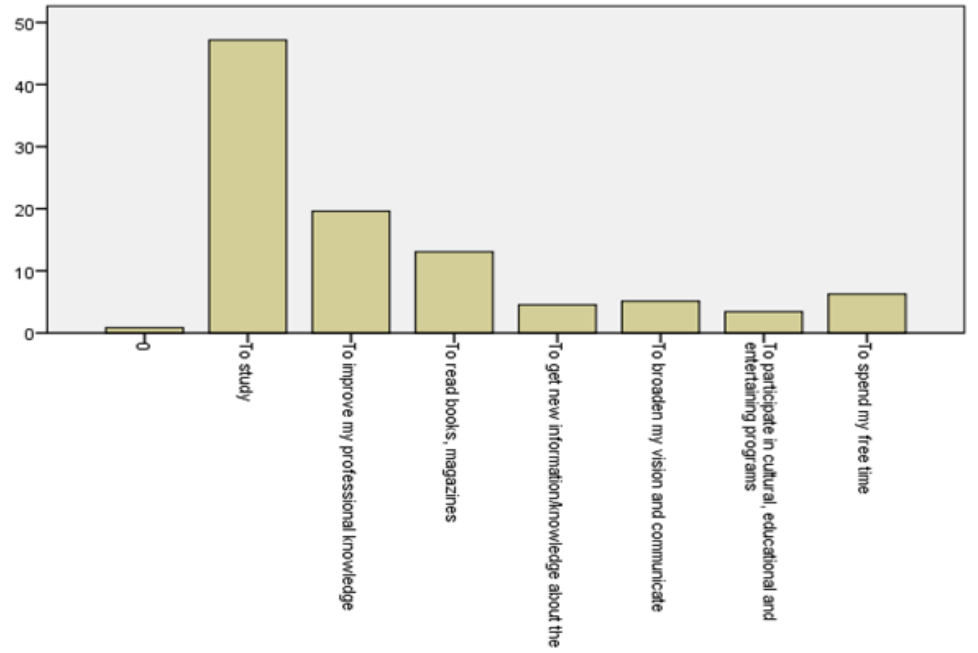

Figure 2: Histogram of question 2 
Goharik Petrosyan, and Artur Tadevosyan

Table 3: Results of question 3

\begin{tabular}{|c|c|c|c|c|c|}
\hline \multicolumn{6}{|c|}{ Question3 } \\
\hline & & \multicolumn{4}{|c|}{ Frequency|PercentValid PercentAccumulated Percent } \\
\hline \multirow[t]{6}{*}{ valid } & 0 & 5 & 4,5 & 4,5 & 4,5 \\
\hline & Luck of spare time & 69 & 61,6 & 61,6 & 66,1 \\
\hline & Insufficient language skills & 12 & 10,7 & 10,7 & 76,8 \\
\hline & I don't like reading in genera & 7 & 6,3 & 6,3 & 83,0 \\
\hline & Other & 19 & 17,0 & 17,0 & 100,0 \\
\hline & Total & 112 & 100,0 & 100,0 & \\
\hline
\end{tabular}

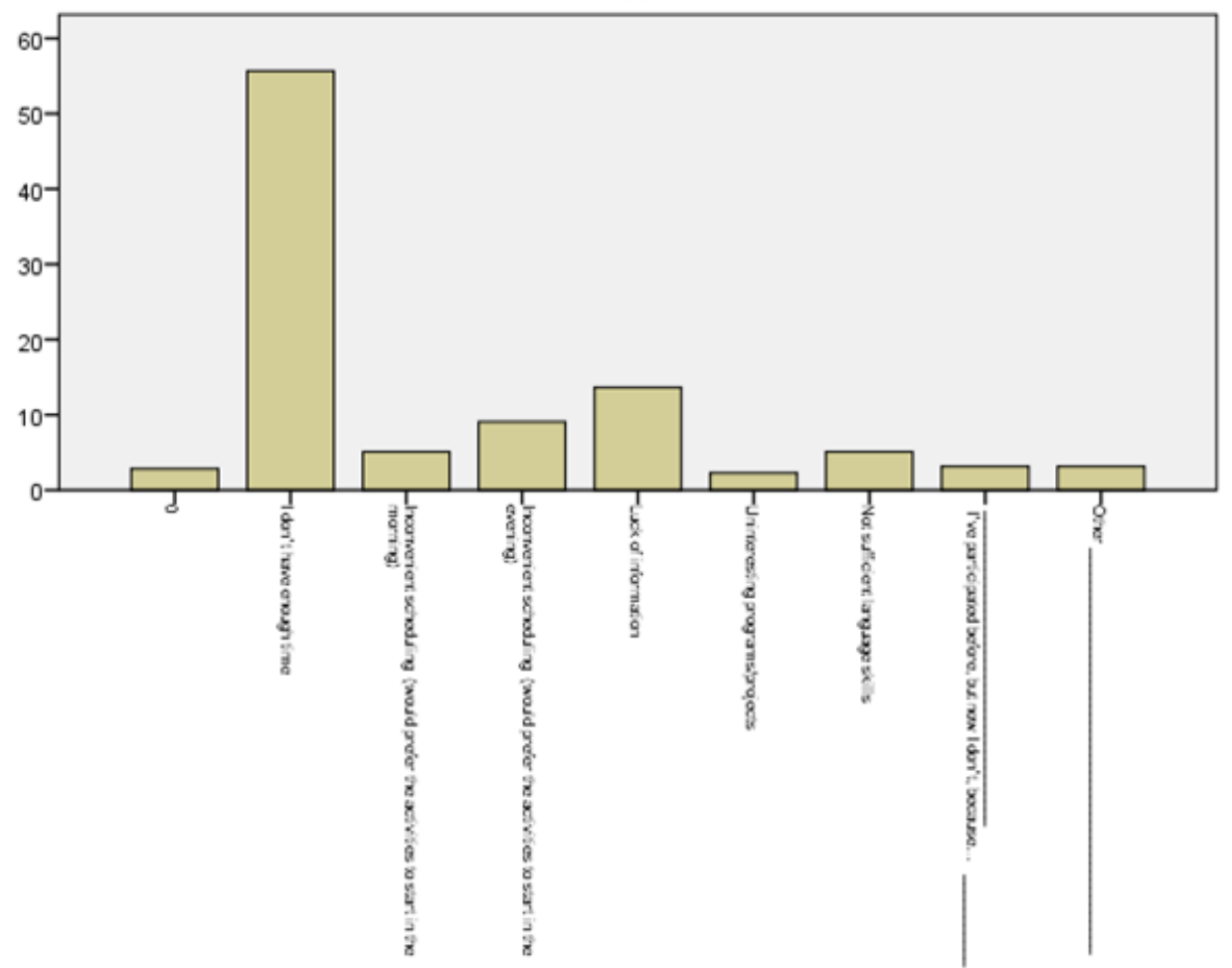

Figure 3: Histogram of question 3

Table 4: Results of question 4

\begin{tabular}{|c|c|c|c|c|c|}
\hline \multicolumn{6}{|c|}{ Question4 } \\
\hline & & \multicolumn{4}{|c|}{ Frequency|PercentValid Percent|Accumulated Percent } \\
\hline \multirow[t]{11}{*}{ valid } & Sociology & 19 & 17,0 & 17,0 & 17,0 \\
\hline & Legal & 3 & 2,7 & 2,7 & 19,6 \\
\hline & Marketing & 4 & 3,6 & 3,6 & 23,2 \\
\hline & nformation technologies & 4 & 3,6 & 3,6 & 26,8 \\
\hline & Art & 2 & 1,8 & 1,8 & 28,6 \\
\hline & Fiction & 1 & ,9 & ,9 & 29,5 \\
\hline & Other & 3 & 2,7 & 2,7 & 32,1 \\
\hline & Psychology & 37 & 33,0 & 33,0 & 65,2 \\
\hline & Politics & 12 & 10,7 & 10,7 & 75,9 \\
\hline & Philosophy & 9 & 8,0 & 8,0 & 83,9 \\
\hline & History & 8 & 7,1 & 7,1 & 91,1 \\
\hline
\end{tabular}


Sociological and Statistical Analysis Based on Survey at The Yerevan American Corner

\begin{tabular}{|c|c|c|c|c|c|}
\hline Pedagogy & 2 & 1,8 & 1,8 & 92,9 \\
\cline { 2 - 5 } & Linguistics & 3 & 2,7 & 2,7 & 95,5 \\
\hline Natural Science & 3 & 2,7 & 2,7 & 98,2 \\
\hline Economics & 2 & 1,8 & 1,8 & 100,0 \\
\hline Total & 112 & 100,0 & 100,0 & \\
\hline
\end{tabular}

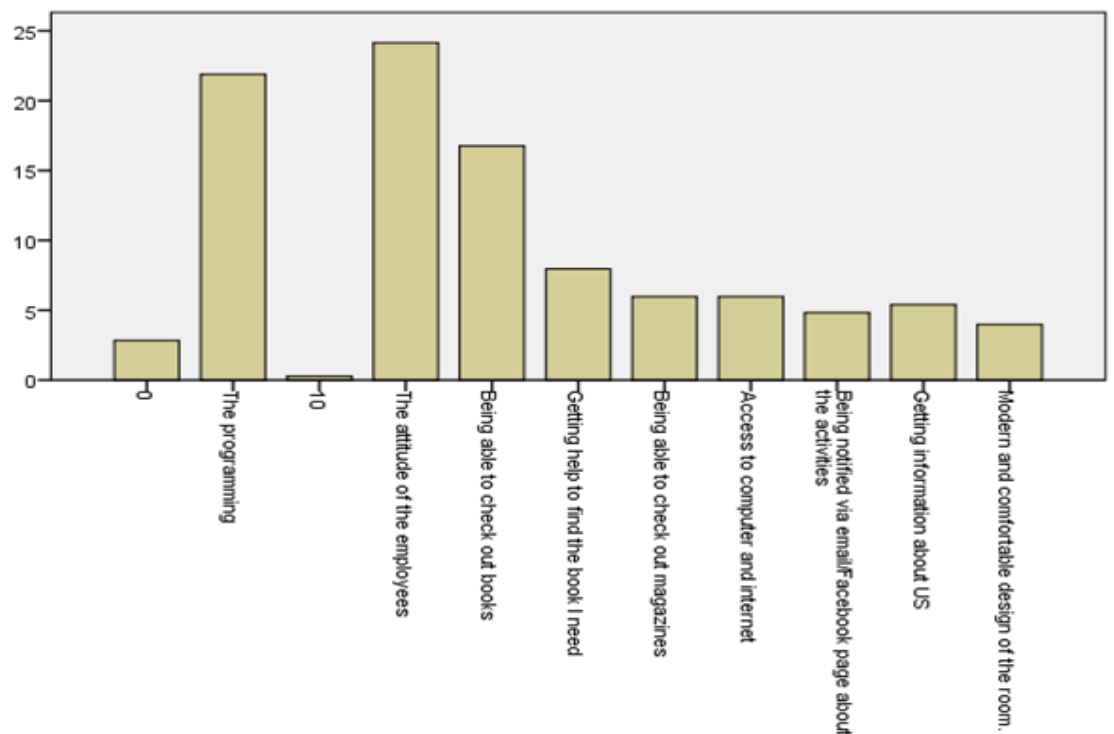

Figure 4: Histogram of question 4

Table 5: Results of question 5

\begin{tabular}{|c|c|c|c|c|c|}
\hline \multicolumn{5}{|c|}{ Question5 } \\
\hline \multirow{2}{*}{ Valid } & Frequency & Percent Valid Percent & Accumulated Percent \\
\cline { 2 - 6 } & 0 & 3 & 2,7 & 2,7 & 2,7 \\
\cline { 2 - 6 } & Facebook page & 64 & 57,1 & 57,1 & 59,8 \\
\cline { 2 - 6 } & 12 & 2 & 1,8 & 1,8 & 61,6 \\
\cline { 2 - 6 } & Corner's web page. & 7 & 6,3 & 6,3 & 67,9 \\
\cline { 2 - 6 } & Via email & 12 & 10,7 & 10,7 & 78,6 \\
\hline & From friends & 15 & 13,4 & 13,4 & 92,0 \\
\cline { 2 - 6 } & From the corner's staff & 9 & 8,0 & 8,0 & 100,0 \\
\cline { 2 - 6 } & Total & 112 & 100,0 & 100,0 & \\
\hline
\end{tabular}

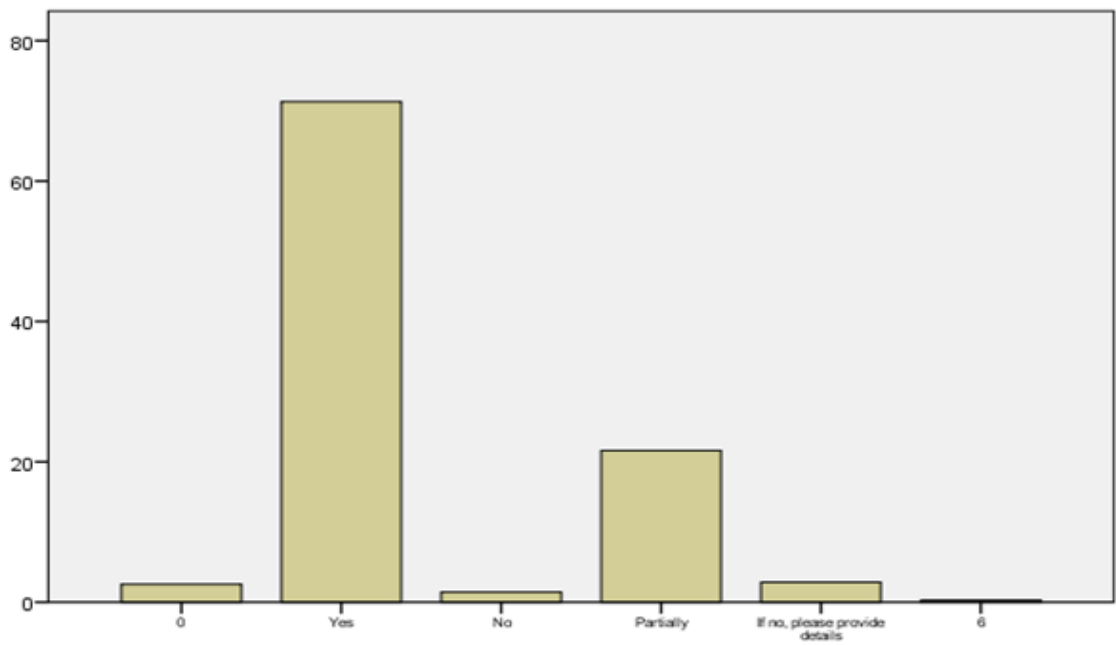

Figure 5: Histogram of question 5 
Goharik Petrosyan, and Artur Tadevosyan

Table 6: Results of question 6

\begin{tabular}{|c|c|c|c|c|c|}
\hline \multicolumn{7}{|c|}{ Question6 } \\
\hline \multirow{3}{*}{ valid } & Frequency & Percent & Valid Percent & Accumulated Percent \\
\cline { 2 - 6 } & Media literacy course/workshop & 33 & 29,5 & 29,5 & 7,1 \\
\cline { 2 - 6 } & Programming course/ workshop & 33 & 29,5 & 29,5 & 36,6 \\
\cline { 2 - 6 } & Photography course/workshop & 24 & 21,4 & 21,4 & 66,1 \\
\cline { 2 - 6 } & Summer school/camp for teenagers. & 7 & 6,3 & 6,3 & 97,5 \\
\cline { 2 - 6 } & Summer school on leadership & 7 & 6,3 & 6,3 & 100,0 \\
\cline { 2 - 6 } & Total & 112 & 100,0 & 100,0 & \\
\hline
\end{tabular}

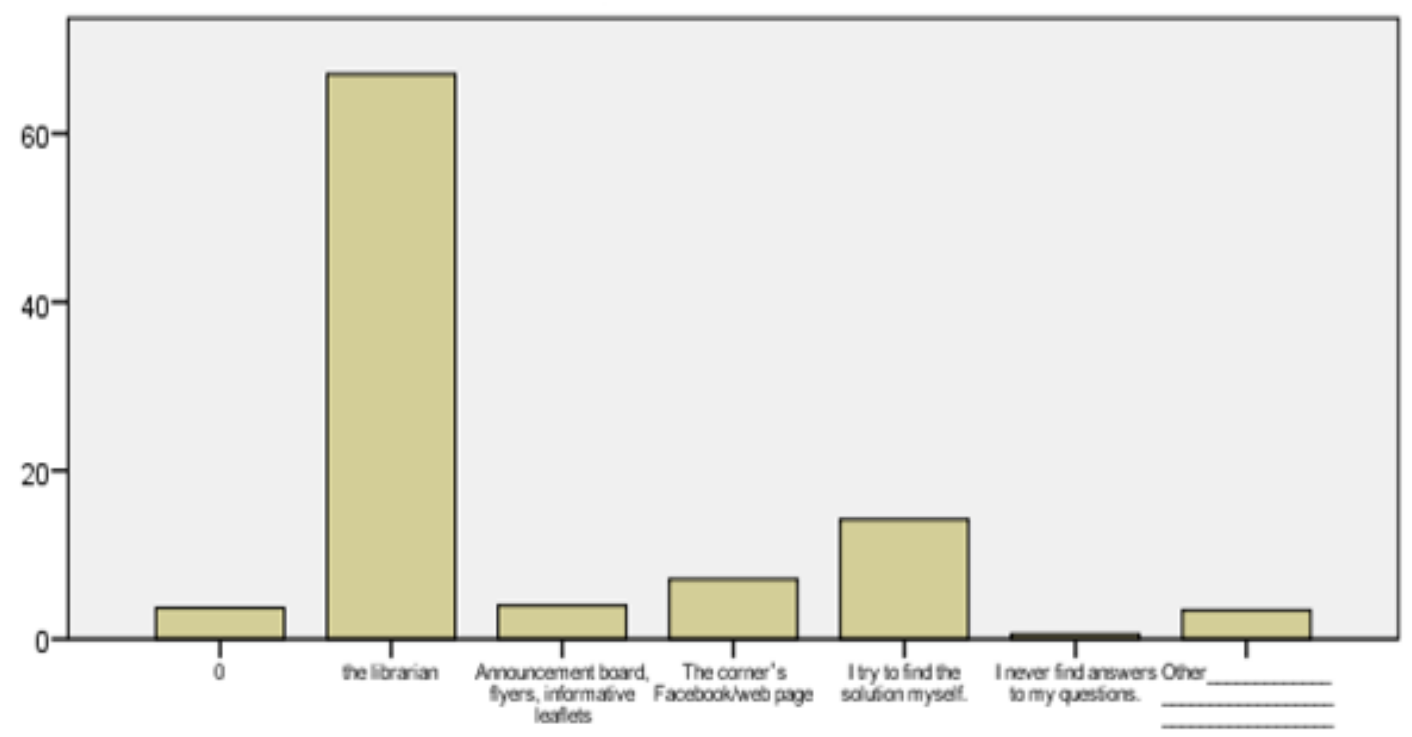

Figure 6: Histogram of question 6

Table 7: Results of question 7

\begin{tabular}{|c|c|c|c|c|c|}
\hline \multicolumn{9}{|c|}{ Question7 } \\
\hline \multicolumn{4}{|c|}{} & Frequency & PercentValid Percent Accumulated Percent \\
\hline \multirow{4}{*}{ valid } & 0 & 18 & 16,1 & 16,1 & 16,1 \\
\cline { 2 - 6 } & Format changes to the clubs & 18 & 16,1 & 16,1 & 32,1 \\
\cline { 2 - 6 } & Improvement/renovation of the room/setting/furniture & 27 & 24,1 & 24,1 & 56,3 \\
\cline { 2 - 6 } & Improvement of technical equipment & 16 & 14,3 & 14,3 & 70,5 \\
\cline { 2 - 6 } & Improvement of the web page & 14 & 12,5 & 12,5 & 83,0 \\
\cline { 2 - 6 } & Other & 19 & 17,0 & 17,0 & 100,0 \\
\cline { 2 - 6 } & \multicolumn{4}{|l}{} \\
\cline { 2 - 6 } & \multicolumn{2}{|l|}{112} & 100,0 & 100,0 & \\
\hline
\end{tabular}




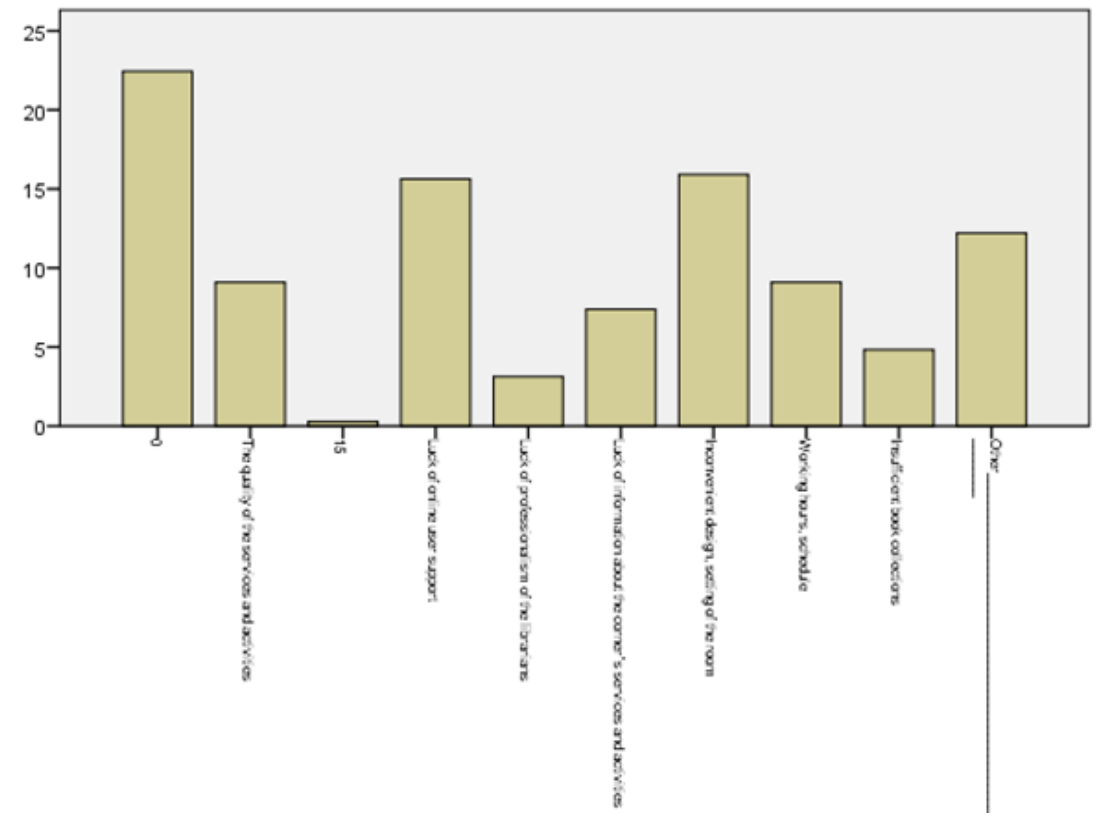

Figure 7: Histogram of question 7

In the same way we structured the second, third, and forth questions, the results of which were recorded and analysed trough the SPSS program and are illustrated by the following tables and histograms.

\section{Conclusions}

The social analysis performed at the Yerevan American Corner with an aim to improve the quality of services and activities has been completed and the following results were obtained: $25.9 \%$ of the surveyed users visit the corner once in two weeks, according to survey question 1, form 1, with 91 frequency of answer. $47.2 \%$ (the majority) of surveyed users visit the corner to study, according to survey question 2, form 1, with 166 frequencies.

$55.7 \%$ (the majority) of surveyed users checks books out and doesn't participant in events because of luck of time, according to survey question 2 , form 1 , with 166 frequencies.

$24.1 \%$ (the majority) of surveyed users have chosen the attitude of the staff to be the thing they like the most about the Corner. This is according to survey question 4, form 1, with 85 frequencies.

$71.3 \%$ (the majority) are content with Corner's book collection. This is according to survey question 5 , form 1 , with 251 frequencies.

$67.0 \%$ (the majority) of surveyed users have said that when having any issues/question while using the corner they get help from the librarians. This is according to survey question 6, form 1, with 236 frequencies.

$22.4 \%$ (the majority) of surveyed users have not answered to survey question 7 , form 1 . With $15.9 \%$ second most popular answer reviled that the surveyed users are not content with the room and would like it to be larger. This is with 56 frequencies.

$20.5 \%$ (the majority) of surveyed users would like the corner to have more books on psychology, according to survey question 8 , form 1 , with 72 frequencies.

$48.0 \%$ (the majority) of surveyed users have not checked out electronic readers or audiobooks. This is according to survey question 9, form 1, with 169 frequencies.

$52.8 \%$ (the majority) of surveyed users would like the room to be quieter, according to survey question 10 , form 1, with 186 frequencies.

According to survey question 1, form 2, $59.8 \%$ (the majority) of surveyed users are interested in English language courses. This answer had 67 frequencies.

$78.6 \%$ (the majority) of surveyed users take part in events to improve their language skills. This is according to survey question 2 , form 2 with 88 frequencies. 
61.6\% (the majority) of surveyed users don't check out book because of insufficient language skills. This is according to survey question 3 , form 2 with 69 frequencies.

$33.0 \%$ (the majority) of surveyed users are interested in events/clubs on the topic of psychology. This is according to survey question 4 , form 2 with 37 frequencies.

$57.1 \%$ (the majority) of surveyed users are notified about the upcoming events of the corner according to question 5 , form 2 with 64 frequencies.

$59 \%$ of responses has been divided equally between two answers: each 29.5 percent of surveyed users would be interested in Media literacy and programming courses. This is according to survey question 6 , form 2 , with 33 frequencies for each. According to accumulative percentage the majority is interested in summer schools.

$24.1 \%$ (the majority) of surveyed users would like the corner to be renovated and improved. This is according to question 7 , form 2 with 27 frequencies.

$38.1 \%$ (the majority) of surveyed users visit the corner once in two weeks. This is according to question 1 , form 3 with 8 frequencies.

$3.3 \%$ (the majority) of surveyed users visit the corner to study, according to question 2, form 3 with 7 frequencies.

$3.3 \%$ (the majority) of surveyed users like the programming of the corner according to question 3 , form 3 with 17 frequencies.

$52.4 \%$ (the majority) of surveyed users are not content with book collection of the corner according to question 4 , form 3 with 11 frequencies.

$85.7 \%$ (the majority) of surveyed users have said that when having any issues/questions while using the corner they get help from the librarians. This is according to survey question 5, form 3, with 18 frequencies.

$33.3 \%$ (the majority) of surveyed users have selected the "Other" option when answering to survey question 6 , form 3 , with 7 frequencies.

$42.9 \%$ (the majority) of surveyed users are interested in fiction books according to survey question 7 , form 3 , with 9 frequencies

$47.6 \%$ (the majority) of surveyed users have not checked out electronic readers and audiobooks. This is according to survey question 8 , form 3 , with 10 frequencies.

$61.9 \%$ (the majority) of surveyed users would like the corner to have a quieter space. This is according to survey question 9, form 3, with 13 frequencies.

$85.7 \%$ (the majority) of surveyed users are interested in English language courses, according to survey question 10 , form 3 , with 18 frequencies.

$81.0 \%$ (the majority) of surveyed users participate in events to improve their language skills, according to survey question 11 , form 3 , with 17 frequencies.

$61.6 \%$ (the majority) of surveyed users don't check out books because of lack of sufficient language skills. This is according to survey question 12 , form 3 , with 69 frequencies.

$33.0 \%$ (the majority) of surveyed users have said that they would like to participate in discussions/events on the topic of psychology. This is according to survey question 13, form 3, with 7 frequencies.

$1.4 \%$ (the majority) of surveyed users are notified about the upcoming event from the corner Facebook page. This is according to survey question 14, form 3, with 15 frequencies.

$4.8 \%$ (the majority) of surveyed users are interested in summer schools. This is according to survey question 15 , form 3 , with 1 frequency.

$47.6 \%$ (the majority) of surveyed users have not answered to question 16, from survey form 3, with 10 frequencies.

The visitor of the City Central library, who don't use the America Corner were surveyed too. 37.2\% of them come to library once in two weeks. This is according to survey question 1, form 4, with 32 frequencies.

$38.4 \%$ knows about the corner, but don't visit it, according to survey question 2 form 4, with 33 frequencies.

$33.7 \%$ were interested to learn about free language courses, according to survey question 3 form 4, with 29 frequencies.

$45.3 \%$ don't check out books from the corner because of insufficient language skills, according to survey question 4 , form 4 , with 39 frequencies.

$22.1 \%$ would be interested in photography lessons according to survay question 5 , form 4 , with 19 frequence.

Taking into consideration the following data obtained through the research, we can optimize the work of American corner regulation through.

International Journal of Engineering Science Technologies 


\section{SOURCES OF FUNDING}

This research received no specific grant from any funding agency in the public, commercial, or not-for-profit sectors.

\section{CONFLICT OF INTEREST}

The author have declared that no competing interests exist.

\section{ACKNOWLEDGMENT}

None.

\section{REFERENCES}

[1] https://www.americancorners.am

[2] https://www.facebook.com/AmericanCornerYerevan/

[3] Collett, D. (2003) Modelling Survival Data in Medical Research (2nd ed). Boca Raton, FL: Chapman and Hall/CRC

[4] Collett, D. (2003) Modeling Binary Data (2nd ed). Boca Raton, FL: Chapman and Hall/CRC

[5] Proudfoot, J., Goldberg, D., Mann, A., Everitt, B. S., Marks, I. M., and Gray, J. A. (2003) Computerised, interactive, multimedia cognitive behavioural therapy for anxiety and depression in general practice. Psychological Medicine, 33, 217-228

[6] Buyul A., Zöfel P. SPSS: The Art of Information Processing. Analysis of statistical data and the restoration of hidden patterns: Per. with him. —SPb: DiaSoftUP, 2005. -- 608 p.

[7] Shackman, Gene. What is Program Evaluation, A Beginner\&\#39; s Guide. Module 3. Methods. The Global Social Change Research Project. 2009. Available at http://www.ideas-int.org

[8] Van Den Berg RG 2015, 1.2.1 SPSS Combining data with syntax and output, SPSS Tutorials,viewed 17 May 2016, \&lt; http://www.spss-tutorials.com/spss-combining-data-with-syntax-and-output/\&gt;.

[9] Van Den Berg RG 2016, SPSS Tutorials, viewed 17 May 2016, \& lt; http://www.spss-tutorials.com/\&gt;.

[10] IBM 2016, IBM Knowledge Center: SPSS Statistics, IBM, viewed 18 May 2016, \&lt;https://www.ibm.com/support/knowledgecenter/SSLVMB/welcome/ \&gt;. 